\title{
Sexual and Voiding Outcomes in Post-Penectomy Penile Cancer Patients
}

\author{
Edward J Park ${ }^{1 *}$, Florian Stroie ${ }^{1}$, Sarah P Psutka ${ }^{1,2}$, Patricia Vidal ${ }^{1,2}$, and Courtney MP Hollowell ${ }^{1,2}$ \\ ${ }^{1}$ Department of Urology, John H Stroger Jr Hospital of Cook County, USA \\ ${ }^{2}$ Department of Urology, Northwestern University, USA
}

Submission: July 13, 2018; Published: August 24, 2018

*Corresponding author: Edward J Park, Department of Surgery, Division of Urology, John H Stroger Hospital of Cook County, Chicago, IL 60612, USA, Tel: (312) 864-5233; Fax: (312) 864-9638; Email: epark3@cookcountyhhs.org

Abstract

Introduction: Penile carcinoma [1] is traditionally managed with total or partial penectomy. Literature regarding patient-reported healthrelated quality of life [2] outcomes following penectomy is lacking. Our objective was to investigate how surgical treatment of penile cancer [3] impacted the patient's sexual, voiding, and psychological function, and overall quality of life.

Materials and Methods: Eleven patients who underwent either partial (8) or radical (3) penectomy between 2004 and 2014 at a single center were retrospectively identified to complete the survey consisting of the validated International Index of Erectile Function (IIEF-15) and the Patient-Reported Outcome Measure for Urethral Stricture Surgery questionnaire.

Results: The median age of the participants was 61 . Of the 8 organ-sparing surgery patients, the median erectile function score was $16 / 30$, the median orgasmic function was 5.5/10, and the median intercourse satisfaction was $5 / 15$. Across all patients, the median sexual desire score was $7 / 10$. The median overall sexual satisfaction was $5 / 10$. Six of the 11 patients reported moderate satisfaction or greater in overall satisfaction with sex life. $80 \%$ reported no or minimal urinary symptoms interfering with daily life. $80 \%$ of the patients reported overall satisfaction with the operation outcome.

Conclusion: To our knowledge, this is the largest assessment of sexual and urinary function using standardized, validated questionnaires in North American post-penectomy patients. We report a mild-to-moderate dysfunction in overall sexual satisfaction. Overall, patients reported minimal bother related to urinary function. The majority of the participants were satisfied with the overall outcome of the surgery.

Keywords: Penile cancer; Quality of Life; Penile carcinoma; Voiding function; Sexual function; Penectomy

Abbreviations: IIEF-15: International Index of Erectile Function Questionnaire; PROM: Patient-Reported Outcome Measures; QOL: Quality of Life; ED: Erectile Dysfunction

\section{Introduction}

Squamous cell carcinoma of the penis is a rare cancer that can affect older, often still sexually active men [4-6]. Fifty-five percent of penile cancer patients are 60 years of age or younger, and $30 \%$ are 55 years or younger[5]. A diagnosis of cancer together with the debilitating morbidity and potential for disfigurement of penile surgery can result in impaired quality of sex life and psychosexual dysfunction [6-8]. While penectomy is traditionally considered the gold standard of treatment for the primary cancer resulting in good oncological outcomes, this approach has been shown to have significant negative impactions for sexual quality of life [8-9]. Furthermore, penectomy is also associated with impaired urination and negatively impacted psychological state. 8 Due to the rarity of this disease, there is a limited pool of patients available for clinical research.6 As such, there is a relative paucity of data describing the impact of surgery for penile cancer on the health-related quality of life of these patients in the medical literature (Table 1). summarizes recent studies in literature evaluating the quality of life outcomes measures in penile cancer patients [9].

In this retrospective study, our objectives were threefold. First, we endeavored to evaluate sexual function [10] among patients treated with partial penectomy using the validated International Index of Erectile Function (IIEF-15) questionnaire. Second, we used a psychometrically robust patient-reported outcome measure (PROM) originally designed to quantify changes in voiding symptoms and health-related quality of life (QOL) following urethral stricture surgery [11]. Finally, we aimed to assess the overall current health state of our patient 
cohort using the standardized five-dimensional EuroQol (EQ-5D-

3L) questionnaire. To our knowledge, this is the largest available

North-American study to use standardized and validated questionnaires to assess all three components of sexual, urinary, and health-related quality of life in penectomy patients.

Table 1: Other Studies Evaluating Post-Penectomy Quality of Life Outcomes.

\begin{tabular}{|c|c|c|c|c|c|c|c|c|c|}
\hline Author & $\begin{array}{c}\text { Bibliography } \\
\text { Reference }\end{array}$ & $\begin{array}{l}\text { Year Study } \\
\text { Published }\end{array}$ & $\begin{array}{c}\text { Patient } \\
\text { Numbers }\end{array}$ & $\begin{array}{c}\text { Study } \\
\text { Location }\end{array}$ & Treatment Used & Study Design & $\begin{array}{c}\text { Mean } \\
\text { Followup } \\
\text { Months }\end{array}$ & $\begin{array}{l}\text { Parametric } \\
\text { Tools Used }\end{array}$ & $\begin{array}{l}\text { Voiding Function } \\
\text { Assessed (Validated } \\
\text { questionnare?) }\end{array}$ \\
\hline Ficarra & [21] & 2000 & 16 & Italy & Partial Penectomy & Retrospective & 69 & $\begin{array}{l}\text { ECOG GHQ } \\
\text { HADS }\end{array}$ & No \\
\hline Romero & {$[12]$} & 2005 & 18 & Brazil & Partial Penectomy & Retrospective & 23.5 & IIEF-15 & No \\
\hline \multirow{4}{*}{ D'Ancona } & \multirow{4}{*}{ [2] } & \multirow{4}{*}{1997} & \multirow{4}{*}{14} & \multirow{4}{*}{ Brazil } & \multirow{4}{*}{ Partial Penectomy } & \multirow{4}{*}{ Retrospective } & \multirow{4}{*}{1.5} & OSFQ & \multirow{4}{*}{ No } \\
\hline & & & & & & & & SPQ & \\
\hline & & & & & & & & GHQ & \\
\hline & & & & & & & & HADS & \\
\hline \multirow{7}{*}{ Windahl } & \multirow{7}{*}{ [1] } & \multirow{7}{*}{2004} & \multirow{7}{*}{36} & \multirow{7}{*}{ Sweden } & \multirow{7}{*}{ Laser Therapy } & \multirow{7}{*}{ Retrospective } & \multirow{7}{*}{36} & $\begin{array}{l}\text { Self-made } \\
\text { sexual }\end{array}$ & \multirow{7}{*}{ No } \\
\hline & & & & & & & & activity & \\
\hline & & & & & & & & $\begin{array}{l}\text { Self-made } \\
\text { sexual }\end{array}$ & \\
\hline & & & & & & & & function & \\
\hline & & & & & & & & ED & \\
\hline & & & & & & & & IIEF-15 & \\
\hline & & & & & & & & Li-Sat-11 & \\
\hline \multirow{4}{*}{ Opjordsmoen } & \multirow{4}{*}{ [3] } & \multirow{4}{*}{1994} & \multirow{4}{*}{30} & \multirow{4}{*}{ Norway } & \multirow{4}{*}{ All Treatments } & \multirow{4}{*}{ Retrospective } & \multirow{4}{*}{80} & DSM III-R & \multirow{4}{*}{ No } \\
\hline & & & & & & & & PAIS & \\
\hline & & & & & & & & GHQ & \\
\hline & & & & & & & & EORTC QLQ & \\
\hline \multirow{3}{*}{ Gulino } & \multirow{3}{*}[24]{} & \multirow{3}{*}{2007} & \multirow{3}{*}{14} & & & Glansectomy/ & & IIEF-15 & \\
\hline & & & & Italy & $\begin{array}{c}\text { Glansectomy/ } \\
\text { Partial Penectomy }\end{array}$ & Partial & 13 & $\begin{array}{l}\text { Bigelow \& } \\
\text { Young }\end{array}$ & No \\
\hline & & & & & & Penectomy & & & \\
\hline Scarberry & [23] & 2015 & 6 & USA & Glansectomy/ & Retrocnective & 52 & IIEF-15 & Yes (Yec) \\
\hline scantily & [LU] & 2010 & 0 & (O) & Partial Penectomy & Neciospective & $J 2$ & PROM & IES $(105)$ \\
\hline & & & & & & & & IIEF-15 & \\
\hline Kinffer & [111] & 2014 & 90 & Netherlandc & Trentmentc & Petrecnective & 466 & SF-36 & Yec (No) \\
\hline Kieffer & [11] & 2014 & 90 & Netnerlanas & ireatments & Ketrospective & 46.6 & IOC ver 2 & res (ivo) \\
\hline & & & & & & & & Self-made & \\
\hline
\end{tabular}

\section{Materials and Methods}

\section{Patient cohort}

We retrospectively identified 34 patients who have undergone either partial or total penectomy between 2004 and 2014 at our institution. The records of these patients were reviewed, and those with confirmed death certificates were excluded from the study $(n=6)$. Patients were called and informed of our study design. A total of 11 patients agreed to participate in our Institutional Review Board approved study.

After providing informed consent via telephone, the 11 patients that chose to participate were then verbally administered the validated questionnaires. Each question and all possible answers were read verbatim by the same interviewer, and the patient was asked to select the appropriate answer with which they agreed.

\section{Research methods}

International Index of Erectile Function (IIEF-15) questionnaire: The IIEF-15 is a 15 -item, multi-dimensional, psychometrically validated instrument that was developed to evaluate male sexual function [12-13]. It is both a sensitive and specific measurement of treatment-related changes of erectile function [14-15]. A score of 0-5 is recorded for each of the 15 questions that examine the five principal domains assessed by 
the IIEF: erectile function (questions 1, 2, 3, 4, 5, 15), intercourse satisfaction (questions 6,7,8), orgasmic function (questions 9 and 10), sexual desire (questions 11 and 12), and overall satisfaction (questions 13 and 14). Three patients in our sample of 11 whom were treated with total penectomy did not report any sexual stimulation within the past four weeks, hence they were excluded from the erectile function, orgasmic function, and intercourse satisfaction domains. We elected to include this subgroup of patients in the overall satisfaction and sexual desire domains.

\section{Urethral stricture surgery patient-reported outcome measure (PROM)}

A review of literature failed to identify a validated PROM designed to specifically assess voiding and health outcomes following penectomy for penile cancer. Therefore, we elected to use a psychometrically robust PROM that was originally designed to quantify changes in voiding symptoms and healthrelated quality of life following urethral stricture surgery [10]. This is a 9-item tool evaluating hesitancy, strength of urinary flow, straining, intermittency, incomplete bladder emptying, post-void dribbling, and interference of urinary symptoms in daily life. Two questions at the end of the questionnaire address overall patient satisfaction with their operation. One patient who had undergone total penectomy with subsequent suprapubic cystostomy placement was excluded from this questionnaire.

\section{Euro Qol EQ-5D-3L questionnaire}

The EQ-5D-3L questionnaire is a standardized and validated tool used to assess overall health-related quality of life by the following 5 dimensions: mobility, self-care, usual activities, pain/discomfort and anxiety/depression.13 Each dimension can be answered in 3 levels: no problems, some problems, and extreme problems.

\section{Results}

Of the 34 patients treated for penile cancer between 2004 and 2014 at our institution, a total of 11 patients agreed to participated in this study (response rate: $32 \%$ ). The median age at surgery was 58.0 years (range: 40-66years). Eight patients underwent organ-sparing glansectomy or partial penectomy and 3 respondents underwent total penectomy. The median time from penectomy to participation in the study was 45 months (range: 22-136 months), with a median age at the time of the study of 61 years (range: 45-73). Overall, 5 (45\%) patients were African American, four (36\%) were Hispanic, one (9\%) was Caucasian, and one (9\%) was Asian. The clinicopathologic features of study participants are summarized in (Table 2).

Table 2: Demographics.

\begin{tabular}{|c|c|c|c|c|c|c|c|c|}
\hline \multirow[b]{2}{*}{ Patient } & \multirow[b]{2}{*}{ Age } & \multirow[b]{2}{*}{ Race } & \multirow{2}{*}{$\begin{array}{l}\text { Age at } \\
\text { Surgery }\end{array}$} & \multicolumn{5}{|c|}{ Operation } \\
\hline & & & & Glansectomy & $\begin{array}{c}\text { Partial } \\
\text { Penectomy }\end{array}$ & $\begin{array}{c}\text { Total } \\
\text { Penectomy }\end{array}$ & $\begin{array}{c}\text { Disease Stage/ } \\
\text { Grade }\end{array}$ & $\begin{array}{c}\text { \# of Months Since } \\
\text { Surgery }\end{array}$ \\
\hline 1 & 45 & Hispanic & 40 & & $\mathrm{x}$ & & pT2N2Mx / 2 & 65 \\
\hline 2 & 46 & $\begin{array}{l}\text { African- } \\
\text { American }\end{array}$ & 41 & & $\mathrm{x}$ & & pT1aN0Mx / 1 & 62 \\
\hline 3 & 47 & Hispanic & 44 & & $\mathrm{x}$ & & pTisN0M0 / n/a & 36 \\
\hline 4 & 56 & Hispanic & 51 & & $\mathrm{x}$ & & pT2N1M0 / 1 & 59 \\
\hline 5 & 57 & Hispanic & 52 & & & $\mathrm{x}$ & pT3N2M0 / 2 & 65 \\
\hline 6 & 61 & Caucasian & 58 & & & $\mathrm{x}$ & pT2NxMx / 1 & 28 \\
\hline 7 & 61 & $\begin{array}{l}\text { African- } \\
\text { American }\end{array}$ & 59 & $\mathrm{x}$ & & & pT2N0Mx / 2 & 22 \\
\hline 8 & 64 & $\begin{array}{l}\text { African- } \\
\text { American }\end{array}$ & 60 & & $\mathrm{x}$ & & pT3N1M0 / 2 & 45 \\
\hline 9 & 65 & $\begin{array}{l}\text { African- } \\
\text { American }\end{array}$ & 63 & & $\mathrm{x}$ & & pT3N0M0 / 1 & 43 \\
\hline 10 & 69 & $\begin{array}{l}\text { African- } \\
\text { American }\end{array}$ & 66 & & $\mathrm{x}$ & & pT3N0M0 / 1 & 39 \\
\hline 11 & 73 & Asian & 61 & & & & $\mathrm{n} / \mathrm{a}$ & 136 \\
\hline Median & 61 & & 58 & & & & & 45 \\
\hline
\end{tabular}

Among the 8 patients who had undergone organ-sparing surgery, the IIEF median erectile function score was $16 / 30$ (range 1-29). The median orgasmic function was 5.5/10 (range $0-8$ ), and the median intercourse satisfaction was $5 / 15$ (range $0-9)$. Accounting for the entire cohort of 8 patients treated with organ-sparing surgery and 3 treated with total penectomy, the median sexual desire score was $7 / 10$ (range 2-10) and the median overall sexual satisfaction was reported at 5/10 (range 2-8).

In the erectile function domain, 2 patients $(25 \%)$ reported severe dysfunction (score $1-10$ ), 3 patients (37.5\%) reported moderate dysfunction (score 11-16), 2 patients (25\%) reported mild to moderate dysfunction (score 17-21), and 1 patient 
(12.5\%) reported no dysfunction (score 26-30). With respect to orgasmic function domain, 4 patients (50\%) felt they experienced the feeling of orgasm or climax "about half the time" while the rest reported "almost never or never". In the intercourse satisfaction domain, 3 patients (37.5\%) reported that sexual intercourse was satisfactory "about half the time" or higher. 1 patient $(12.5 \%)$ was only satisfied "a few times", while the remaining 4 patients (50\%) reported that they were "almost never or never" satisfied. 4 patients (50\%) felt that sexual intercourse was "highly enjoyable" or "fairly enjoyable". 1

Table 3: Scoring of the five domains of sexual function from the IIEF-15. patient $(12.5 \%)$ reported that sexual intercourse was "not very enjoyable". The rest of the patients "did not attempt intercourse" over the past 4 weeks.

Across all 11 patients, in the overall sexual satisfaction domain of the IIEF-15 survey, 1 patient reported being "mostly satisfied" with overall sex life, while 5 patients reported "moderate satisfaction" with overall sex life. 2 patients mentioned they were "about equally satisfied or dissatisfied". 2 patients were "moderately dissatisfied", and 1 patient was "very dissatisfied". IIEF-15 domain results are summarized in Table 3.

\begin{tabular}{|c|c|c|c|c|c|}
\hline \multirow[b]{2}{*}{ Patient } & \multicolumn{5}{|c|}{ IIEF-15 Score Per Domain (Score Range) } \\
\hline & $\begin{array}{c}\text { Erectile Function } \\
\qquad(0-30)\end{array}$ & $\begin{array}{c}\text { Orgasmic Function } \\
(0-10)\end{array}$ & Sexual Desire (0-10) & $\begin{array}{c}\text { Intercourse } \\
\text { Satisfaction }(0-15)\end{array}$ & $\begin{array}{c}\text { Overall Satisfaction } \\
(0-10)\end{array}$ \\
\hline 1 & 12 & 2 & 7 & 3 & 5 \\
\hline 2 & 16 & 7 & 10 & 8 & 4 \\
\hline 3 & 20 & 5 & 8 & 6 & 8 \\
\hline 4 & 29 & 8 & 7 & 9 & 8 \\
\hline 5 & $\mathrm{n} / \mathrm{a}$ & $\mathrm{n} / \mathrm{a}$ & 6 & $\mathrm{n} / \mathrm{a}$ & 6 \\
\hline 6 & $\mathrm{n} / \mathrm{a}$ & $\mathrm{n} / \mathrm{a}$ & 2 & $\mathrm{n} / \mathrm{a}$ & 3 \\
\hline 7 & 1 & 0 & 3 & 0 & 2 \\
\hline 8 & 16 & 6 & 5 & 9 & 8 \\
\hline 9 & 19 & 6 & 10 & 4 & 3 \\
\hline 10 & 4 & 1 & 10 & 0 & 5 \\
\hline 11 & $\mathrm{n} / \mathrm{a}$ & $\mathrm{n} / \mathrm{a}$ & 4 & $\mathrm{n} / \mathrm{a}$ & 7 \\
\hline Median & 16 & 5.5 & 7 & 5 & 5 \\
\hline
\end{tabular}
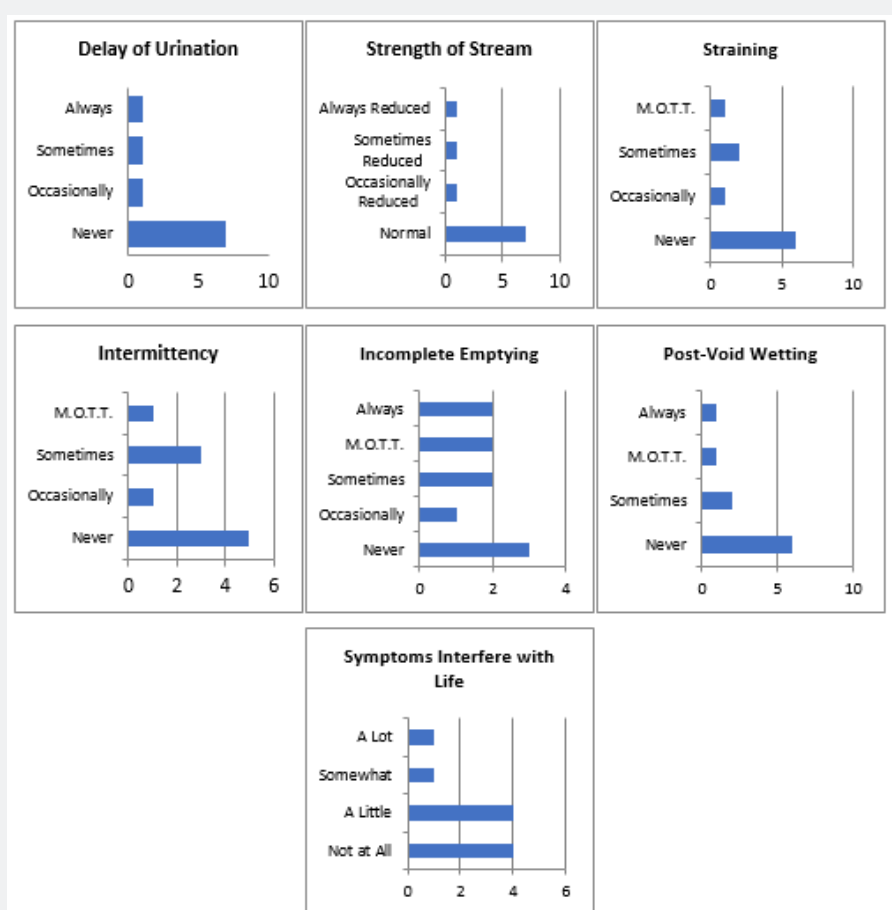

Figure 1: Patient-Reported Urinary Function Following Surgery.

${ }^{*}$ M.O.T.T. $=$ Most of the time 
With respect to urinary function, utilizing the urethral stricture surgery PROM among the 10 patients who voided routinely, $7 / 10$ patients reported no delay with starting urination and described their urinary flow as "normal". 6/10 patients reported that they "never" strained to urinate, while $3 / 10$ patients "occasionally" or "sometimes" strained and 1/10 patients reported straining to urinate "most of the time". 4/10 patients reported no urinary symptoms interfering with daily life, while 5 patients reported that symptoms interfered with life «a little» or «somewhat.» Overall, 8/10 patients reported that they were satisfied with the operation outcome. More specifically, 2/10 patients reported being "very satisfied", 6/10 patients stated they were "satisfied", and the remainder was "unsatisfied" with the outcome of their operation. Detailed domain results are presented in (Figure 1).

The five dimensions of the EQ-5D-3L aim to assess overall health-related quality of life. 7/11 patients reported "no problems in walking about", while the rest had "some problems walking about". 9/11 patients reported "no problems with selfcare" and 8/11 patients reported "no problems with performing usual activities". 8/11 patients did not endorse any overall "pain/discomfort" or "anxiety/depression" [16,17].

\section{Discussion}

Penile cancer is a rare disease that affects less than $1 \%$ of males in the United States [1]. High rates of early circumcision have been postulated to explain the low rates of penile carcinoma seen in the United States [3]. Due to the rarity of the disease, there are few studies available that have explored the postoperative outcomes regarding quality of life measures after extirpation. In this retrospective review, we identified 34 cases of penile cancer treated with either partial or total penectomy over a period of 10 years of whom 11 patients consented to participate in the current survey study. Median time from surgery to the interview date was 45 (range 22-136) months. Eight patients underwent organ-preserving surgery and the rest were treated with total penectomy. To our knowledge, our study is the largest study to date that has evaluated the sexual and urinary function of postpenectomy patients in the United States.

Although the goal of organ-sparing penectomy is to spare penile nerve function and maximize penile stump length to permit intercourse, decrease in sexual function and quality is unavoidable in most cases [18-19]. Furthermore, both partial and radical penectomy are known to negatively impact patient confidence, self-image, mental health, and overall sexual function [12]. As expected, when compared to a series of 109 healthy males without documented erectile dysfunction (ED) who completed the IIEF-15 questionnaire, our cohort scored $37 \%$ lower on erectile function, $44 \%$ lower on orgasmic function, $38 \%$ lower on intercourse satisfaction, $32 \%$ lower on overall satisfaction [10]. These findings are consistent with a 2014 Dutch study by Kieffer et al that also reported predictably lower domain scores in post-penile cancer surgery patients when comparing to the same 109 controls in the prior study. The sample of 90 penile cancer patients in this study reported $50 \%$ lower erectile function, orgasmic function, intercourse satisfaction, and $41 \%$ lower overall satisfaction [9].

The 3 patients who've undergone a radical penectomy reported some degree of overall sexual satisfaction despite being unable to have intercourse. This suggests that modalities other than intercourse can still provide sexual satisfaction in these patients, which echoes the importance of providing pre- and post-operative counselling to discuss and explore other means in achieving sexual gratification.

In contrast to diminished sexual quality and function, most patients reported satisfactory voiding function with $60 \%$ reporting "never" experiencing post-void wetting, 20\% only "sometimes" and the rest (20\%) "most of the time" or "all of the time". Overall, $45 \%$ of patients reported being unaffected by their urinary symptoms with further $45 \%$ acknowledging that urinary symptoms interfered with their life "a little or somewhat". Kieffer et al observed that $83 \%$ of patients experienced urinary leakage with $91 \%$ reporting satisfaction with urinary function [8]. Although we report good overall urinary outcomes, it is important to acknowledge that the PROM utilized herein was not specifically validated in penectomy patients, and its generalizability across various interventions and health care systems has not yet been established [9]. To our knowledge, a questionnaire specific for penile cancer and its effects on voiding function has yet to be developed [20].

Depression is not uncommon in cancer patients and may exist in up to $50 \%$ of patients with penile cancer [4]. A prospective study of 43 patients from China found that anxiety and depression were significantly increased after partial penectomy, whereby more than half of the sample study experienced psychological problems.16 Albeit in our small sample of 11 post-penectomy patients, only $27 \%(\mathrm{n}=3)$ reported "moderate" anxiety or depression. Of the three patients who admitted to feelings of anxiety or depression, only one was unsatisfied with the operation outcome, and the rest reported overall satisfaction with the outcome of their operation. The high overall satisfaction rate and the low depression/anxiety rate were surprising considering the diminished sexual outcomes. The low rate of impairment in the general health state in our cohort was also somewhat unexpected. Ficarra et al. [21] demonstrated significant impairment in the general state of health in partial penectomy patients 17 . Though we do not report significant impairments in health-related quality of life, these measures are subjective and can fluctuate as a response to a whole host of internal and external factors [21-23]. However, our findings may suggest that penectomy may not be as detrimental, both physically and psychologically, as has previously been reported [19].

There are several limitations of the current study that are important to acknowledge. In total, our response rate to our 
survey was 32\%, which raises the potential for responder bias and may in part explain why we note relatively favorable operation outcomes among our cohort. Furthermore, the cohort is limited in size, preluding our ability to adjust for potential confounding factors such as the extent of inguinal lymphadenectomy, occurrence of postoperative complications, lymphedema, prior exposure to chemotherapy/radiation, and other comorbidities such as benign prostatic hyperplasia, diabetes and peripheral vascular disease, or smoking history, which may also influence sexual and voiding related outcomes. Due to the retrospective nature of this study and inconsistent documentation, we were not able to evaluate patients' sexual, voiding, and overall health status prior to surgical management. Prospectively assessing these domains prior to surgery using validated patient-reported instruments would provide better understanding of the degree of impact on patients' quality of life. Lastly, the majority of our patients were of African American and Hispanic ethnicities (45\% and 36\%, respectively), who were treated for penile cancer at an institution that primarily caters to an at-risk inner-city underserved population, limiting the generalizability of our results to that of the broader NorthAmerican population. Despite the limitations, this study does provide valuable insight into postoperative penectomy patients' quality of life involving sexual and voiding functions, and its psychological impacts.

\section{Conclusion}

Penile cancer is a rare disease with low incidence and prevalence, and opportunities to study the quality of life in postpenectomy patients are limited. To our knowledge, this is the largest study of sexual and urinary function using standardized, validated questionnaires in North American post-penectomy patient population. The majority of our cohort reported intact sexual and urinary function. Emphasis on patient counselling to assist post-penectomy patients in navigating their sexual, urinary, and psychological challenges could potentially improve the quality across all of these domains, and would be an important area of interest for future studies [24].

\section{References}

1. Windahl T, Skeppner E, Andersson SO, Fugl-Meyer KS (2004) Sexual function and satisfaction in men after laser treatment for penile carcinoma. J Urol 172(2): 648-651.

2. D’Ancona CA, Botega NJ, De Moraes C, Lavoura NS, Jr, Santos JK, et al. (1997) Quality of life after partial penectomy for penile carcinoma. Urology 50(4): 593-596.

3. Opjordsmoen S, Waehre H, Aass N, Fossa SD (1994) Sexuality in patients treated for penile cancer: patients' experience and doctors' judgement. Br J Urol 73(5): 554-560.

4. Barnholtz-SJS, Maldonado JL, Pow-Sang J, Giuliano AR (2007) Incidence trends in primary malignant penile cancer. Urol Oncol 25(5): 361-367.

5. Narayana AS, Olney LE, Loening SA, Weimar GW, Culp DA (1982) Carcinoma of the penis: analysis of 219 cases. Cancer. 49(10): 21852191.
6. Maddineni SB, Lau MM, Sangar VK (2009) Identifying the needs of penile cancer sufferers: A systematic review of the quality of life, psychosexual and psychosocial literature in penile cancer. BMC Urol 9: 8.

7. Mahesan T, Hegarty PK, Watkin NA (2016) Advances in PenilePreserving Surgical Approaches In The Management Of Penile Tumors. Urol Clin North Am 43: 427-434.

8. Maden C1, Sherman KJ, Beckmann AM, Hislop TG, Teh CZ (1993) History of circumcision, medical conditions, and sexual activity and risk of penile cancer. J Natl Cancer Inst 85(1): 19-24.

9. Sosnowski R, Marta K, Mariola K, Jan Karol W, Kuczkiewicz O, et al. (2016) Quality of life in penile carcinoma patients - posttotal penectomy. Cent European J Urol 69(2): 204-211.

10. Horenblas S, van Tinteren H, Delemarre JF, Boon TA, Moonen LM, et al. (1992) Squamous cell carcinoma of the penis. II. Treatment of the primary tumor. J Urol 147(6): 1533-1538.

11. Kieffer JM, Djajadiningrat RS, van Muilekom EA, Graafland NM, Horenblas S et al. (2014) Quality of life in patients treated for penile cancer. J Urol 192(4): 1105-1110.

12. Romero FR, Romero KR, Mattos MA, Garcia CR, Fernandes Rde C et al. (2005) Sexual function after partial penectomy for penile cancer. Urology 66(6): 1292-1295.

13. Jackson MJ, Sciberras J, Mangera A, Brett A, Watkin N (2011) Defining a patient-reported outcome measure for urethral stricture surgery. Eur Urol 60(1): 60-68.

14. Rosen RC, Cappelleri JC, Gendrano N (2002) The International Index of Erectile Function (IIEF): A state-of-the-science review. Int J Impot Res 14(4): 226-244.

15. Cappelleri JC, Tseng LJ, Luo X, Stecher V, Lue TF (2016) Simplified Interpretation of the Erectile Function Domain of the International Index of Erectile Function. J Sex Med 13(4): 690-696.

16. Sansalone S, Silvani M, Leonardi R, Vespasiani G, Iacovelli V (2017) Sexual outcomes after partial penectomy for penile cancer: results from a multi-institutional study. Asian J Androl 19(1): 57-61.

17. The EuroQol Group (1990) EuroQol-a new facility for the measurement of health-related quality of life. Health Policy. 16(3): 199-208.

18. Pompeo AC, Zequi Sde C, Pompeo AS (2015) Penile cancer: organsparing surgery. Curr Opin Urol 25(2): 121-128.

19. Guimarães GC, Rocha RM, Zequi SC, Cunha IW, Soares FA (2011) Penile cancer: epidemiology and treatment. Curr Oncol Rep 13(3): 231-239.

20. Yu C, Hegun C, Longfei L, Longfei L, Minfeng C, et al. (2016) Sexual Function after Partial Penectomy: A Prospectively Study from China. Sci Rep 6: 21862.

21. Ficarra V, Righetti R, Pilloni S, Balzarro M, Schiavone D, et al. (2000) General state of health and psychological well-being in patients after surgery for urological malignant neoplasms. Urol Int 65(3): 130-134.

22. Kiebert GM (1997) Quality of life as an outcome measure in cancer clinical trials. Eur Urol 31(suppl 1): 56-64.

23. Scarberry K, Angermeier KW, Montague D (2015) Outcomes for OrganPreserving Surgery for Penile Cancer. Sex Med 3(2): 62-66.

24. Gulino G, Sasso F, Falabella R, Bassi PF (2007) Distal urethral reconstruction of the glans for penile carcinoma: results of a novel technique at 1-year of follow-up. J Urol 178(3): 941-944. 
(C) This work is licensed under Creative

BY DOI: 10.19080/JOJUN.2018.06.555678

Your next submission with Juniper Publishers will reach you the below assets

- Quality Editorial service

- Swift Peer Review

- Reprints availability

- E-prints Service

- Manuscript Podcast for convenient understanding

- Global attainment for your research

- Manuscript accessibility in different formats

(Pdf, E-pub, Full Text, Audio)

- Unceasing customer service

Track the below URL for one-step submission https://juniperpublishers.com/online-submission.php 